\title{
A Qualitative Study of a Rotating Shaft \\ Having a Slant Crack
}

\author{
Dr. Sabah Mohammed Jamel \\ Professor
}

\author{
Ziad Shakeeb Al-Sarraf \\ Assistant Leacture
}

Mechanical Engineering Department, Mosul University

\begin{abstract}
In this study, a qualitative analysis of a transverse vibration of a rotor system with a crack that grows at an angle of 45 degrees toward the axis of the shaft is presented. Based on the assumption that the bending stiffness of the shaft changes synchronously with the opening / closing behavior of the crack caused by the torsional vibration of the shaft, the equation of motion of a simple rotor system with a shaft having a slant crack is represented by a differential equation with parametric excitation in fixed coordinate system rotating at the operation speed of the rotor. Finally, it is shown by the solution that the steady-state response of the rotor system with a slant crack on its shaft induced by imbalance contains the frequencies represented by
\end{abstract}

$\omega_{n}=m \Omega+\frac{n \omega_{T}}{2}, m=1,2,3, \ldots ., n=0,1,2, \ldots$

Key words : Shaft, cracked motor, vibration,slant crack.

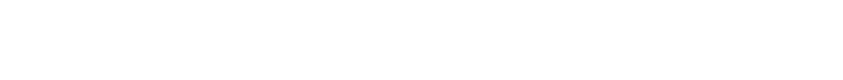

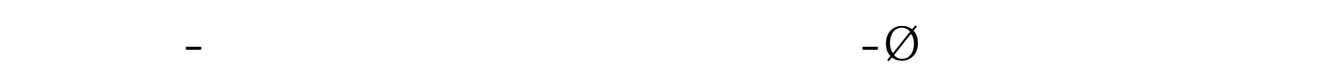

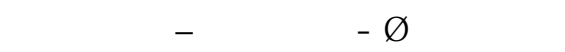 \\ rU゚ ŤKE
}

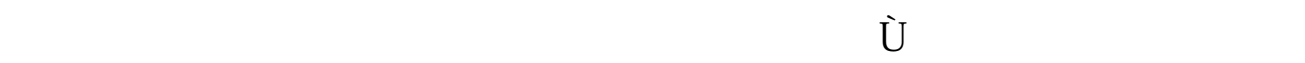

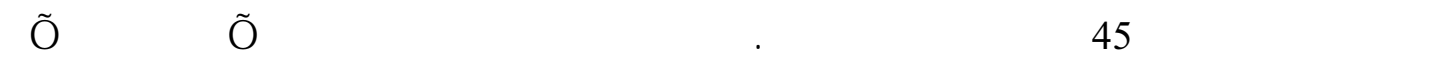

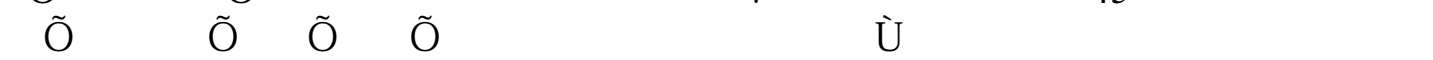

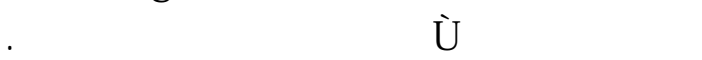

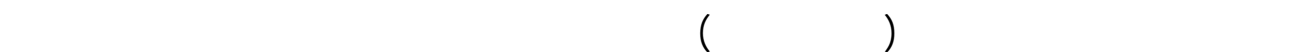

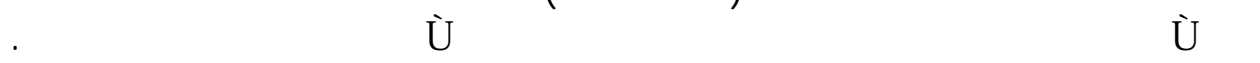

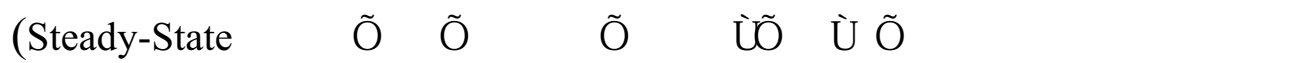

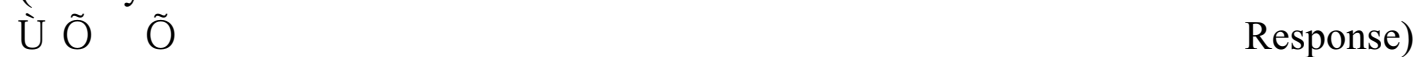

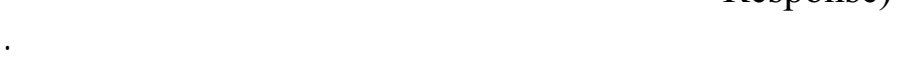

$$
\omega_{n}=m \Omega+\frac{n \omega_{T}}{2}, m=1,2,3, \ldots, n=0,1,2, \ldots
$$




\begin{tabular}{llll} 
Al-Rafidain Engineering & Vol.15 & No.4 & 2007 \\
\hline
\end{tabular}

\section{Nomenclature:}

$\begin{array}{ll}\mathrm{m} & \text { Mass of the disk }(\mathrm{kg}) \\ \mathrm{G} & \text { Center of gravity } \\ \mathrm{g} & \text { Acceleration }\left(\mathrm{m} / \mathrm{sec}^{2}\right) \\ \mathrm{t} & \text { Time }(\mathrm{sec}) \\ \sigma_{1} \& \sigma_{2} & \text { Principal stresses }\left(\mathrm{N} / \mathrm{m}^{2}\right) \\ \mathrm{K}_{\mathrm{o}} & \text { Stiffness of the shaft } \\ \mathrm{K}_{\zeta} \& \mathrm{~K}_{\eta} & \text { Stiffness in the } \zeta \text { and } \eta \text { direction } \\ \nu & \text { Crack depth ratio } \\ \varepsilon & \text { Eccentricity of shaft }(\mathrm{mm}) \\ \Omega & \text { Operating speed of the rotor }(\mathrm{rad} / \mathrm{sec}) \\ \omega_{o} & \text { Natural Frequency of the Rotor }(\mathrm{rad} / \mathrm{sec}) \\ \omega_{T} & \text { Torsional (Circular) Frequency }(\mathrm{rad} / \mathrm{sec}) \\ \theta_{\xi}, \theta_{\eta} & \text { Phases of bending stiffness in } \xi \& \eta \\ \phi & \text { Phase angle (degree) } \\ \gamma & \text { Damping ratio } \\ \Lambda=\lambda+j \cdot n \frac{\omega_{T}}{2} & \text { Parametric Excitation } \\ B=\left(\omega_{o}{ }^{2}-\Omega^{2}\right) I & \text { Parametric Excitation } \\ \mathrm{I}, \mathrm{H} & \text { Matrix } \\ \lambda & \text { Introduce the Notation } \\ \mathrm{n} & \end{array}$

\section{Introduction}

Since the mid-seventies the dynamic behavior of cracked shaft has been investigated increasingly because damages in steam turbines, generators, pumps, and other machines occurred quite often. This caused costly shutdowns of entire plants and was sometimes followed by the total loss of the machine. An increased level of reliability has been demanded for such rotating machinery as steam turbine, generator $[1,2]$.

Consequently, various studies on the abnormal behavior of rotating machinery have been undertaken and systems for monitoring failure in the rotating machinery have also been developed. It is very important for improving the reliability of the rotating machinery to understand the dynamics of the rotor system with a cracked shaft; if allowed to progress, the crack may be causing a failure of the shaft.

Through the previous studies, many useful results have been obtained regarding the dynamics of the rotor system with a cracked shaft. However, these studies have treated the case where a crack grows transversely toward the axis or the 


\section{Jamel : A Qualitative Study of a Rotating Shaft Having a Slant Crack}

rotor. The Crack is caused by the change in the stiffness of the shaft, according to how opened or closed by the deflection of the shaft. This characteristic is applied to the monitoring system for detecting cracks in the rotating machinery $[2,3]$.

The transversal crack of the shaft, as mentioned above, occurs from the fatigue of the shaft material due to an excessive bending moment. On the other hand, there exists a case where the crack grows at an angle 45 degree toward the axis on the surface of the shaft, occurring from the fatigue of the shaft due to torsional moment.

The stiffness of the shaft is through to be closely related with the opening closing behavior of the crack. Depending on the torsional vibration of the rotor system; therefor the rotor system with a slant crack occurring from torsion may induce a different vibration from that of one with a transverse crack.

Recently use of the large rotating machines driven under operating systems induce torsional vibration, such as daily start-stop operations, or thyristor motor.

This requires the operators to through vibration measurements, and to detect slant as well as transversal cracks [4].

\section{Theoretical Considerations}

It is know that slant cracks change the stiffness of the shaft just as transversal cracks. However the slant crack occurs due to the torsional vibration of the shaft, therefore the opening / closing behavior of the crack depends on torsional vibration. Then,

Firstly, study and investigate the relationship between the stiffness of the shaft with a slant crack and the torsional vibration of the shaft.

Secondly apply the characteristics of the shaft with a slant to a simple rotor model, therefore the transverse vibration of a rotor system with a slant crack is analyzed qualitatively.

\subsection{The torsional vibration and the stiffness of the shaft}

From the Strength of Material [5]. The torsional moment $M$ applied to a shaft causes on its surface the principal stresses $\sigma_{1}$ and $\sigma_{2}$ lying orthogonal to each other at an angle of 45 degree with the axis of the shaft as shown in the (Fig 1).

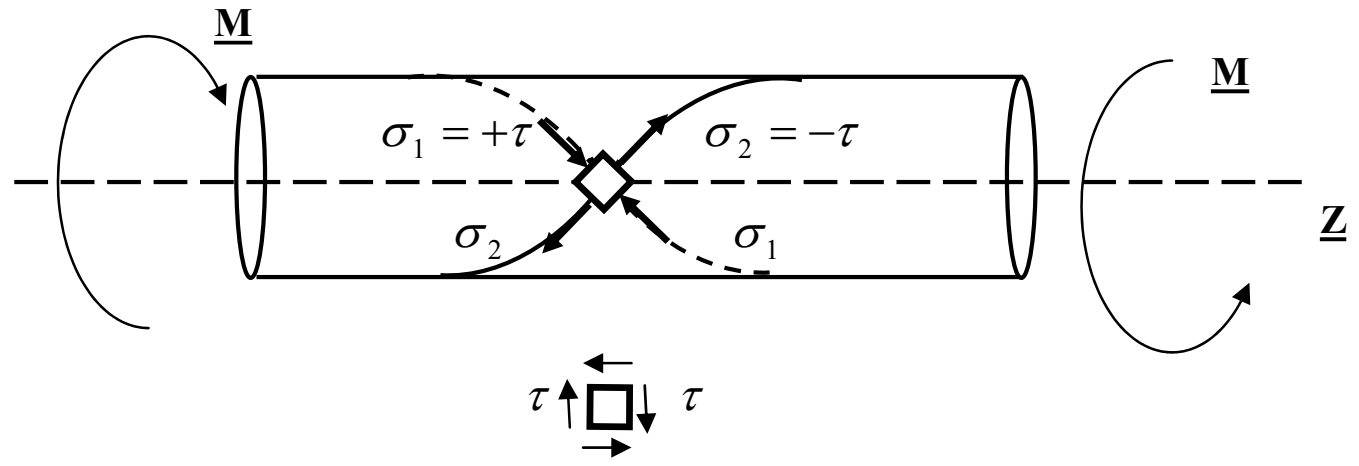

Fig 1. The Principal stress directions of a shaft under torsional moment 


\begin{tabular}{llll} 
Al-Rafidain Engineering & Vol.15 & No.4 & 2007 \\
\hline
\end{tabular}

Applying a torsional vibratory moment to the shaft under the conditions of smaller amplitude over a longer period of time, A slant crack grows along the primary stress line as shown in (Fig.2).
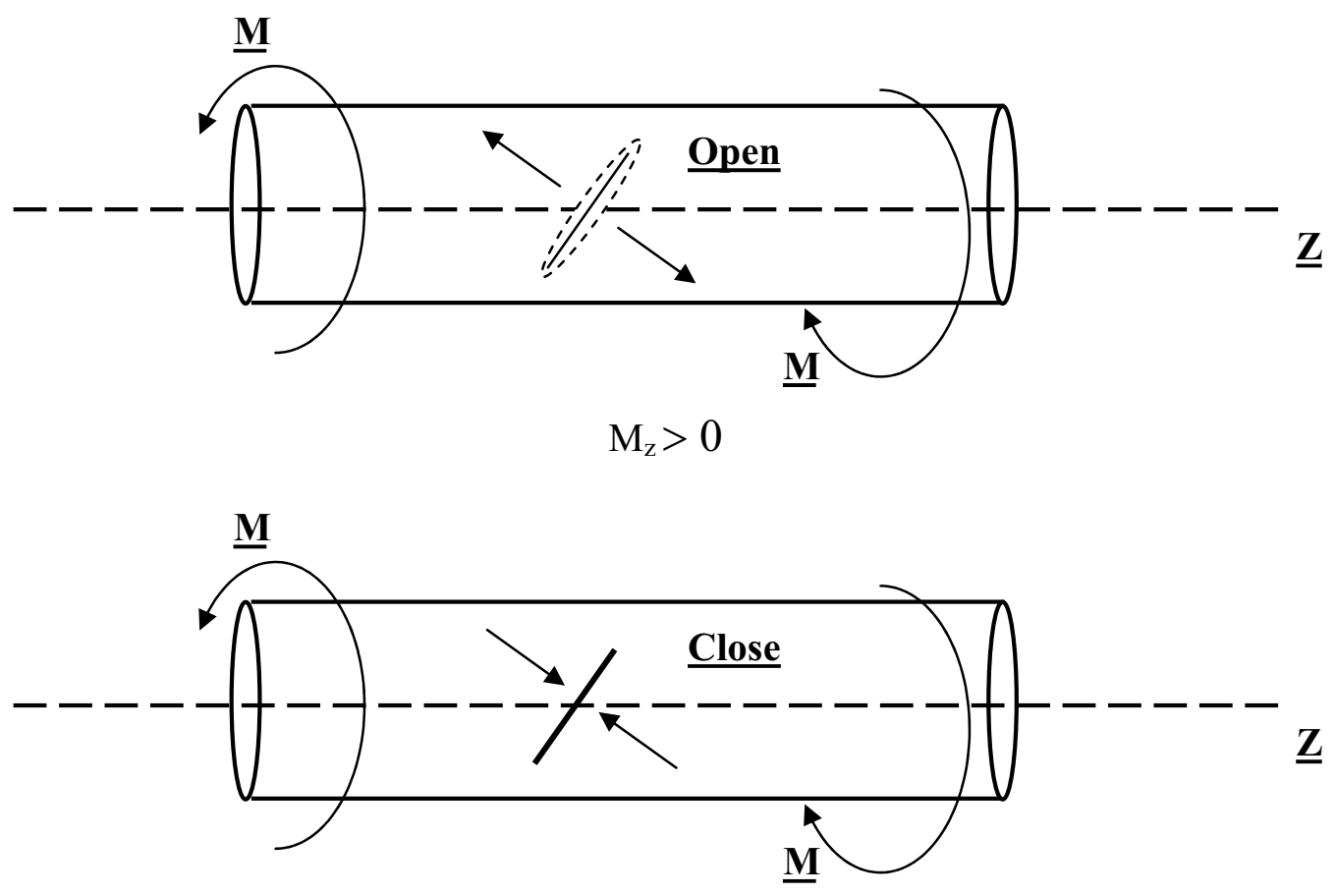

$$
\mathrm{M}_{\mathrm{z}}<0
$$

Fig 2. The Opening / Closing behavior of the slant crack

The positive torsional moment shown in (Fig.2-a) causes tension in such a way as to open the crack, On the other hand the negative torsional moment shown in (Fig.2-b) causes compression in such a way to close the crack. The moment of polar area of this section of the shaft will be higher, when the negative moment is applied.

As the stiffness of the shaft is proportional to the inertia of the section of the shaft., it is expected that the stiffness of the shaf, with the slant crack changes according to the opening / closing condition of the crack. As the crack continuos opening and closing alternatively, with the same periods, the torsional vibration of the shaft, the stiffness of the shaft will change synchronously with the torsional vibration.

On the assumption that the change in the stiffness is proportional to the torsional deflection angle of the shaft. The stiffness of the shaft is represented as follows in figure (Fig.3) [6]. So as 

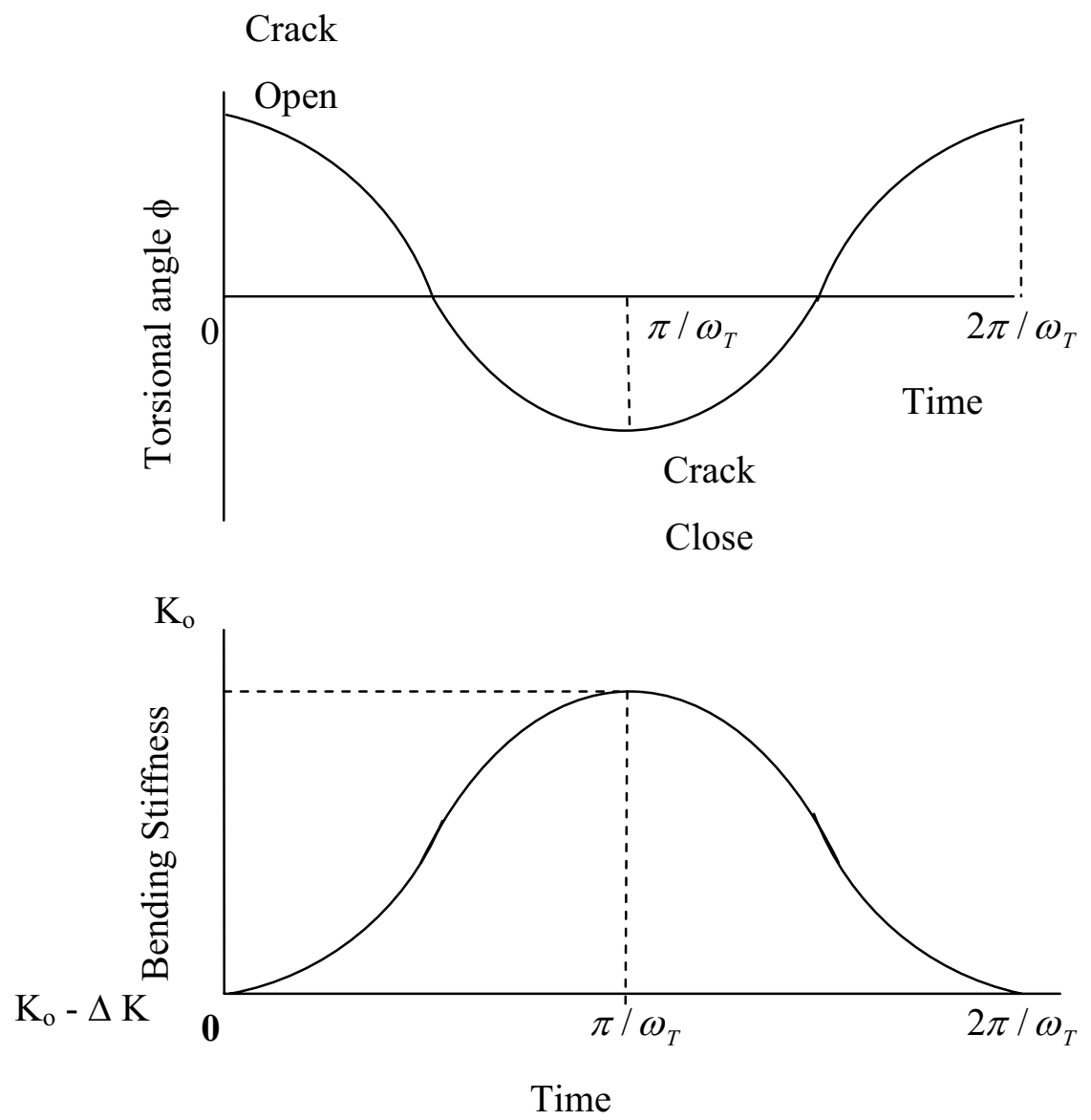

Fig 3. Bending stiffness of the shaft and torsional vibration

$K=K_{o}-\frac{\Delta K}{2}\left(1+\cos \omega_{T} t\right)$

where $K_{0}$ and $\left(K_{0}-\Delta K\right)$ are the stiffness values of the shaft when the crack close and open, respectively and $\omega_{T}$ is the circular frequency of the torsional vibration and $t$ is time. 


\begin{tabular}{llll} 
Al-Rafidain Engineering & Vol.15 & No.4 & 2007 \\
\hline
\end{tabular}

\subsection{The equation of motion}

A simple rotor model is considered consisting of a rigid disk and a shaft with a slant crack supported by two rigid bearing, as shown in (Fig.4) [7].

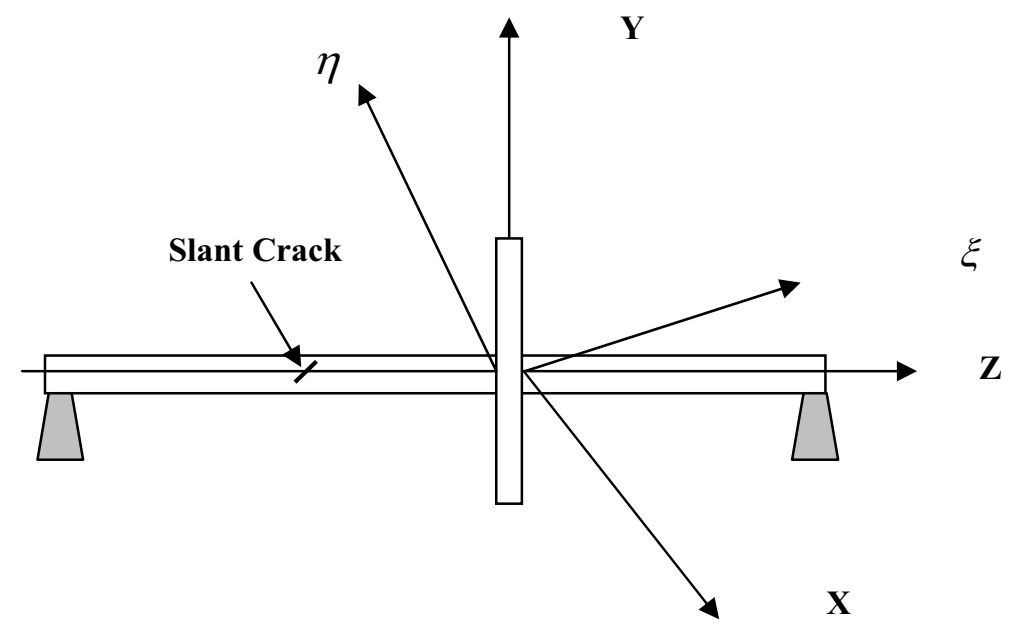

Fig 4. The model of the shaft with slant crack

Using fixed coordinate system $(\mathrm{x}, \mathrm{y}, \mathrm{z})$ and a rotating coordinate system $(\zeta, \eta$, $z)$. The $z$-axis originates from the disk along the line passing through the centers of each bearing, and the $x$-axis and y-axis lie horizontally and vertically, respectively. The rotating coordinate system $(\zeta, \eta, z)$ rotates around the z-axis at the speed the same as the operating speed $\Omega$ of the rotor. The equation of motion in the rotor is expressed in the fixed coordinate system as [9].

$$
\begin{aligned}
& \left\{\begin{array}{l}
x^{\prime \prime} \\
y^{\prime \prime}
\end{array}\right\}+\frac{K_{\xi}-K \eta}{2 m}\left\langle\begin{array}{cc}
-\cos 2 \Omega t & -\sin 2 \Omega t \\
-\sin 2 \Omega t & \cos 2 \Omega t
\end{array}\right)\left\{\begin{array}{l}
x \\
y
\end{array}\right\} \\
& +\frac{K_{\xi}-K \eta}{2 m}\left\{\begin{array}{l}
x \\
y
\end{array}\right\}=\varepsilon \Omega^{2}\left\{\begin{array}{l}
\cos (\Omega t+\varphi) \\
\sin (\Omega t+\varphi)
\end{array}\right\}+\left\{\begin{array}{l}
0 \\
g
\end{array}\right\}
\end{aligned}
$$

where $\mathrm{m}$ is the mass of the disk, $\mathrm{K}_{\mathrm{z}}$ and $\mathrm{K} \eta$ are the stiffness of the shaft in the $\zeta$ and $\eta$ direction, respectively, $\varepsilon$ is the eccentricity of the center of the gravity G, of the disk, $\phi$ is the phase angle of $\mathrm{G}$, and $\mathrm{g}$ is the acceleration of gravity. The relationship between the rotating and fixed coordinate system is

$$
\left\{\begin{array}{l}
x \\
y
\end{array}\right\}=\left\langle\begin{array}{cc}
\cos \Omega t & -\sin \Omega t \\
\sin \Omega t & \cos \Omega t
\end{array}\right\rangle\left\{\begin{array}{l}
\xi \\
\eta
\end{array}\right\}
$$


Substituting Eq. (3) into Eq.(2) leads to

$$
\begin{aligned}
& \left\{\begin{array}{l}
x^{\prime \prime} \\
y^{\prime \prime}
\end{array}\right\}+\left\{\begin{array}{cc}
0 & -2 \Omega \\
2 \Omega & 0
\end{array}\right)\left\{\begin{array}{l}
\xi^{\prime} \\
\eta^{\prime}
\end{array}\right\}+\left\langle\begin{array}{cc}
K_{\xi} / m-\Omega^{2} & 0 \\
0 & K_{\eta} / m-\Omega^{2}
\end{array}\right)\left\{\begin{array}{l}
\xi \\
\eta
\end{array}\right\} \\
& =\delta \Omega^{2}\left\{\begin{array}{l}
\cos \varphi \\
\sin \varphi
\end{array}\right\}-g\left\{\begin{array}{l}
\sin \Omega t \\
\cos \Omega t
\end{array}\right\}
\end{aligned}
$$

Assuming $\mathrm{K}_{\zeta}, \mathrm{K}_{\eta}$ take the form of Eq. (1), they can be written as follows :

$$
\begin{aligned}
& K_{\xi}=K_{o}-\frac{\Delta K_{\xi}}{2}\left(1+\cos \left(\omega_{T} t+\theta_{\xi}\right)\right. \\
& K_{\eta}=K_{o}-\frac{\Delta K_{\eta}}{2}\left(1+\cos \left(\omega_{T} t+\theta_{\eta}\right)\right.
\end{aligned}
$$

Where $\theta_{\xi}, \theta_{\eta}$ are the respective phases of bending stiffness, Hence, we consider the case of

$\theta_{\xi}=\theta_{\eta}=0$

And introducing the following Parameters:

$\omega_{o}=\sqrt{K_{o} / m}$

$v=\frac{\Delta K_{\xi}+\Delta K_{\eta}}{2 K_{o}}$

where $\omega_{0}$ is the natural frequency of the transverse vibration of the rotor when the crack closes, $v$ is the crack depth ratio. Substituting Eqs. (5) - (8) into Eq. (4), and rearranging we obtain

$$
\begin{aligned}
& \left\{\begin{array}{l}
\xi^{\prime \prime} \\
\eta^{\prime \prime}
\end{array}\right\}+\left\{\begin{array}{cc}
0 & -2 \Omega \\
2 \Omega & 0
\end{array}\right)\left\{\begin{array}{l}
\xi^{\prime} \\
\eta^{\prime}
\end{array}\right\}+\left(\omega_{o}{ }^{2}-\Omega^{2}\right)\left\{\begin{array}{l}
\xi \\
\eta
\end{array}\right\} \\
& =\Omega^{2}\left\{\begin{array}{l}
\cos \varphi \\
\sin \varphi
\end{array}\right\}-g\left\{\begin{array}{l}
\sin \Omega t \\
\cos \Omega t
\end{array}\right\}
\end{aligned}
$$

or

$$
\xi^{\prime \prime}+H \xi^{\prime}+\left\{\left(\omega_{o}^{2}-\Omega^{2}\right) I\right\}=f
$$


Where

$$
\begin{aligned}
& I=\left[\begin{array}{ll}
1 & 0 \\
0 & 1
\end{array}\right], H=\left[\begin{array}{cc}
0 & -2 \Omega \\
2 \Omega & 0
\end{array}\right], \\
& \varepsilon=\left\{\begin{array}{l}
\xi \\
\eta
\end{array}\right\}, f=\delta \Omega^{2}\left\{\begin{array}{l}
\cos \varphi \\
\sin \varphi
\end{array}\right\}-g\left\{\begin{array}{l}
\sin \Omega t \\
\cos \Omega t
\end{array}\right\}
\end{aligned}
$$

\subsection{The transverse vibration of the rotor with a slant crack $[5,6]$}

According to Eq.(10) which includes parametric excitation, there exist a periodic solution, which can be obtained by setting the right-hand side equal to zero $[8,9,10]$ :

$\xi^{\prime \prime}+H \xi^{\prime}+\left(\omega_{o}^{2}-\Omega^{2}\right) I \xi=0$

The solution of Eq.(11) is of the form

$\xi=e^{\lambda t} \sum_{n=-\infty}^{+\infty} \xi^{\prime} n e^{j n . \omega_{T} / 2 . t}$

Substituting Eq.(12) into Eq.(11) leads to

$\left.e^{\lambda t} \sum_{n=-\infty}^{+\infty}\left\{\left(\Lambda^{2}{ }_{n} I+\Lambda_{n} H+B\right)\right) \xi_{n 0}^{\prime}\right\} e^{j n . \omega_{T} / 2 . t}=0$

Where

$$
\begin{gathered}
\Lambda_{n}=\lambda+j \cdot n \frac{\omega_{T}}{2} \\
B=\left(\omega_{o}{ }^{2}-\Omega^{2}\right) I
\end{gathered}
$$

Eq.(13) is equivalent to the following pair of equations:

$$
\begin{aligned}
& {\left[\begin{array}{ccc}
\Lambda^{2}{ }_{-2} I+\Lambda_{-2} H+B & & \\
& \Lambda^{2}{ }_{o} I+\Lambda_{o} H+B & \\
& & \Lambda^{2}{ }_{-2} I+\Lambda_{-2} H+B
\end{array}\right]\left\{\begin{array}{c}
\xi_{-2}^{\prime} \\
\xi_{0}^{\prime} \\
\xi_{+2}^{\prime}
\end{array}\right\}=0---(14)} \\
& {\left[\begin{array}{cc}
\Lambda_{-1} H+B \\
-\frac{v \omega_{o}^{2}}{2} & \Lambda_{+1} H+B
\end{array}\right]\left\{\begin{array}{l}
\xi_{-1}^{\prime} \\
\xi_{+1}^{\prime}
\end{array}\right\}=0}
\end{aligned}
$$

Therefore. Eq.(14) \& (15) have infinite solution .but, 
$\lambda=\lambda_{r}+j \lambda_{i}$

$\xi_{n}^{\prime}=\left\{\begin{array}{l}\zeta_{n}^{\prime} \\ \eta_{n}^{\prime}\end{array}\right\}$

And Eq. (3) and Eq. (13) are transformed to fixed coordinate system;

$\left\{\begin{array}{l}x \\ y\end{array}\right\}=\left\{\begin{array}{l}2 e^{\lambda r t} \sum_{n=-\infty}^{+\infty} \operatorname{Re}\left(\left(\zeta_{n}^{\prime}+j \eta_{n}^{\prime}\right) e^{j\left(\lambda_{r}+\Omega+n-\omega_{T} / 2\right) . t}\right. \\ 2 e^{\lambda r t} \sum_{n=-\infty}^{+\infty} \operatorname{Re}\left(\left(\zeta_{n}^{\prime}-j \eta_{n}^{\prime}\right) e^{j\left(\lambda_{r}+\Omega+n-\omega_{T} / 2\right) . t}\right.\end{array}\right\}$

Eq.(18) shows that the transient response of the rotor with a slant crack contains the frequencies so therefore :

$\omega_{n}=\lambda_{i}+\Omega \pm n \frac{\omega_{T}}{2} ; n=0,1,2,3,4,5$

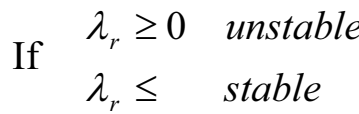

By another way, the steady state response of the cracked rotor system will be obtained by neglecting the gravitational term of the right-hand in Eq.(10), and assuming the solution as

$\xi=\sum_{n=\infty}^{+\infty} \xi_{n}^{\prime} e^{j n . \omega_{T} / 2 . t}$

Then the equation becomes

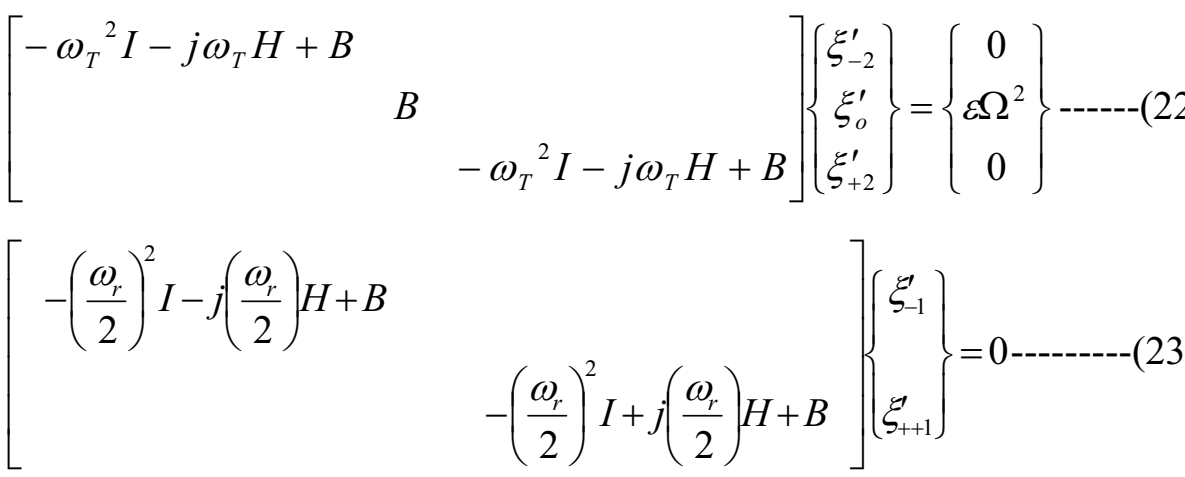

Putting equations (22) \& (23) into Eq.(21), the steady state response in the rotating coordinate system can be obtained by : 


\section{$\begin{array}{llll}\text { Al-Rafidain Engineering } & \text { Vol.15 } & \text { No.4 } & 2007\end{array}$}

$$
\left\{\begin{array}{l}
x \\
y
\end{array}\right\}=\left\{\begin{array}{l}
2 e^{\lambda r t} \sum_{n=-\infty}^{+\infty} \operatorname{Re}\left(\left(\zeta_{n}^{\prime}+j \eta_{n}^{\prime}\right) e^{j\left(\lambda_{r}+\Omega+n-\omega_{T} / 2\right), t}\right. \\
2 e^{\lambda r t} \sum_{n=-\infty}^{+\infty} \operatorname{Re}\left(\left(\eta_{n}^{\prime}-j \zeta_{n}^{\prime}\right) e^{j\left(\lambda_{r}+\Omega+n-\omega_{T} / 2\right), t}\right.
\end{array}\right\}
$$

Equation (24) represent the steady state response of cracked rotor system induced by imbalance of the fixed coordinate system contains the frequencies by:

$\omega_{n}=\Omega \pm n \frac{\omega_{T}}{2} ; n=0,1,2,3,4,5$,

\section{Results Of Isotropic Rotor}

The response can be calculated by using a linear acceleration method for the initial condition of steady state response of the uncracked rotor system [10,11]. And by adding the damping to recognize the gab between the real response and the initial condition, Therefore the values of the parameters used in the analysis are listed in table (1)

\begin{tabular}{|l|l|}
\hline Natural Frequency of the Rotor $\left(\omega_{o}\right)$ & $960 \mathrm{rad} / \mathrm{sec}(152.78 \mathrm{~Hz})$ \\
\hline Torsional Frequency $\left(\omega_{T}\right)$ & $163.4 \mathrm{rad} / \mathrm{sec}(26 \mathrm{~Hz})$ \\
\hline Operation Speed of the Rotor $(\Omega)$ & $503 \mathrm{rad} / \mathrm{sec}(80 \mathrm{~Hz})$ \\
\hline Eccentricity of the disk $(\varepsilon)$ & $1.0 \mathrm{~mm}$ \\
\hline \hline Gravitational acceleration $(\mathrm{g})$ & $9800 \mathrm{~m} / \mathrm{s}^{2}$ \\
\hline Damping Ratio $(\tau)$ & 0.01 \\
\hline
\end{tabular}

Table 1. The Values of the model used in calculation

When the slant crack grows uniformly around the shaft, the anisotropy of the stiffness of the shaft is negligible, thus: -

$$
\Delta K_{\xi}=\Delta K_{\eta}
$$

Then Eq.(2) can be rewritten in the form

$$
\begin{aligned}
& x^{\prime \prime}+\omega_{o}{ }^{2}\left\{1-v\left(1+\cos \omega_{T} t\right)\right\} x=\varepsilon \Omega^{2} \cos \Omega t \\
& y^{\prime \prime}+\omega_{o}{ }^{2}\left\{1-v\left(1+\cos \omega_{T} t\right)\right\} y=\varepsilon \Omega^{2} \sin \Omega t+g
\end{aligned}
$$

\section{Discussion}

The dynamic response in the fixed coordinate system can be conveniently obtained in a direct calculation by using Eq.(27).

(Fig.5, $6 \& 7$ ) Shows the numerical results of the steady-state response with isotropic cracked rotor system, for the case of $\mathrm{v}=0.0,0.1,0.3$ and 0.5 . In the case of 


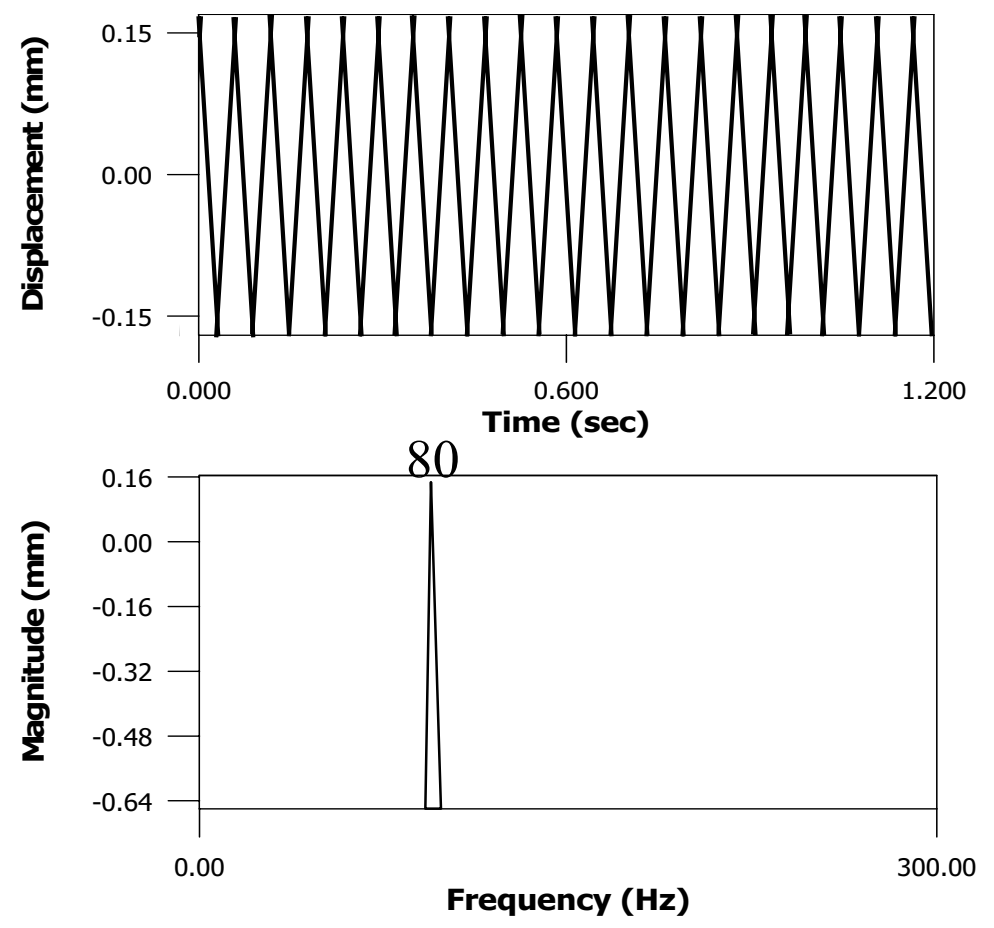

$$
\begin{aligned}
& v=0.0 \\
& \mu=0.0
\end{aligned}
$$
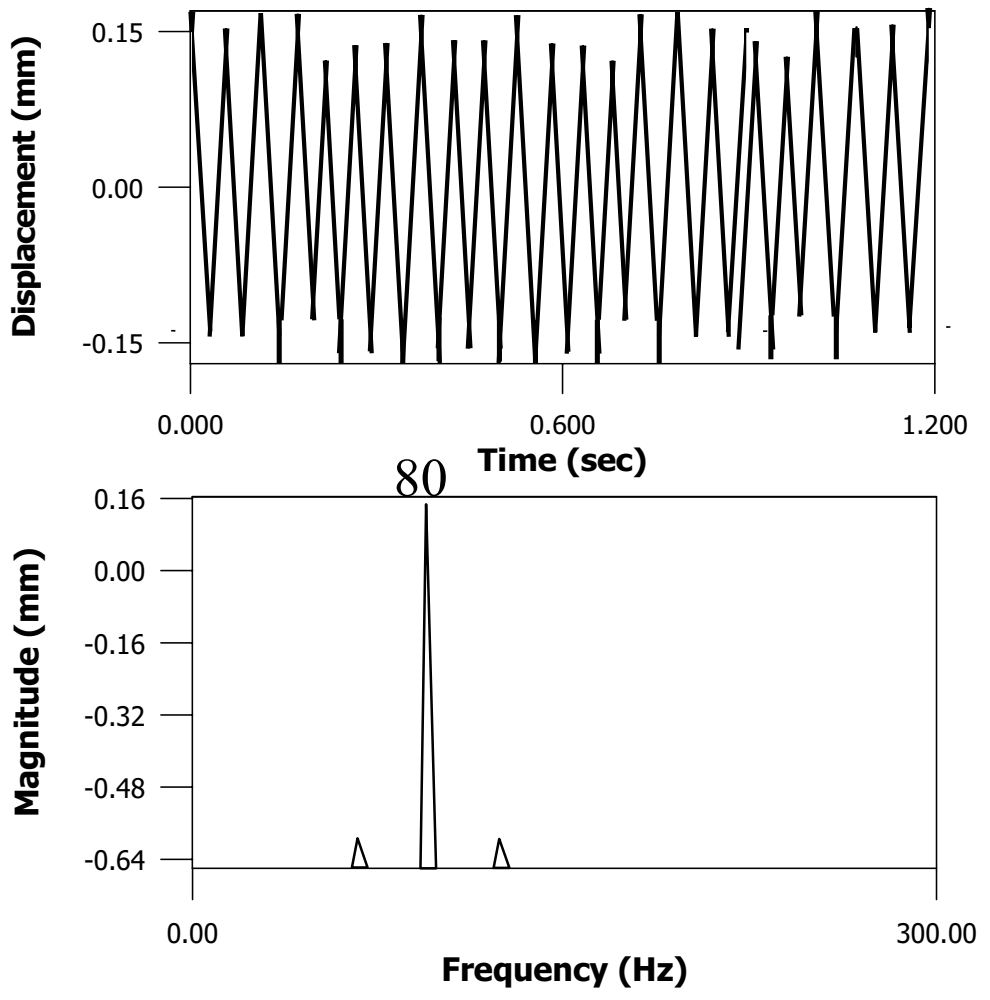

$v=0.1$

$\mu=0.0$

Fig.5 The Steady-State Response with Isotropic Cracked Shaft 


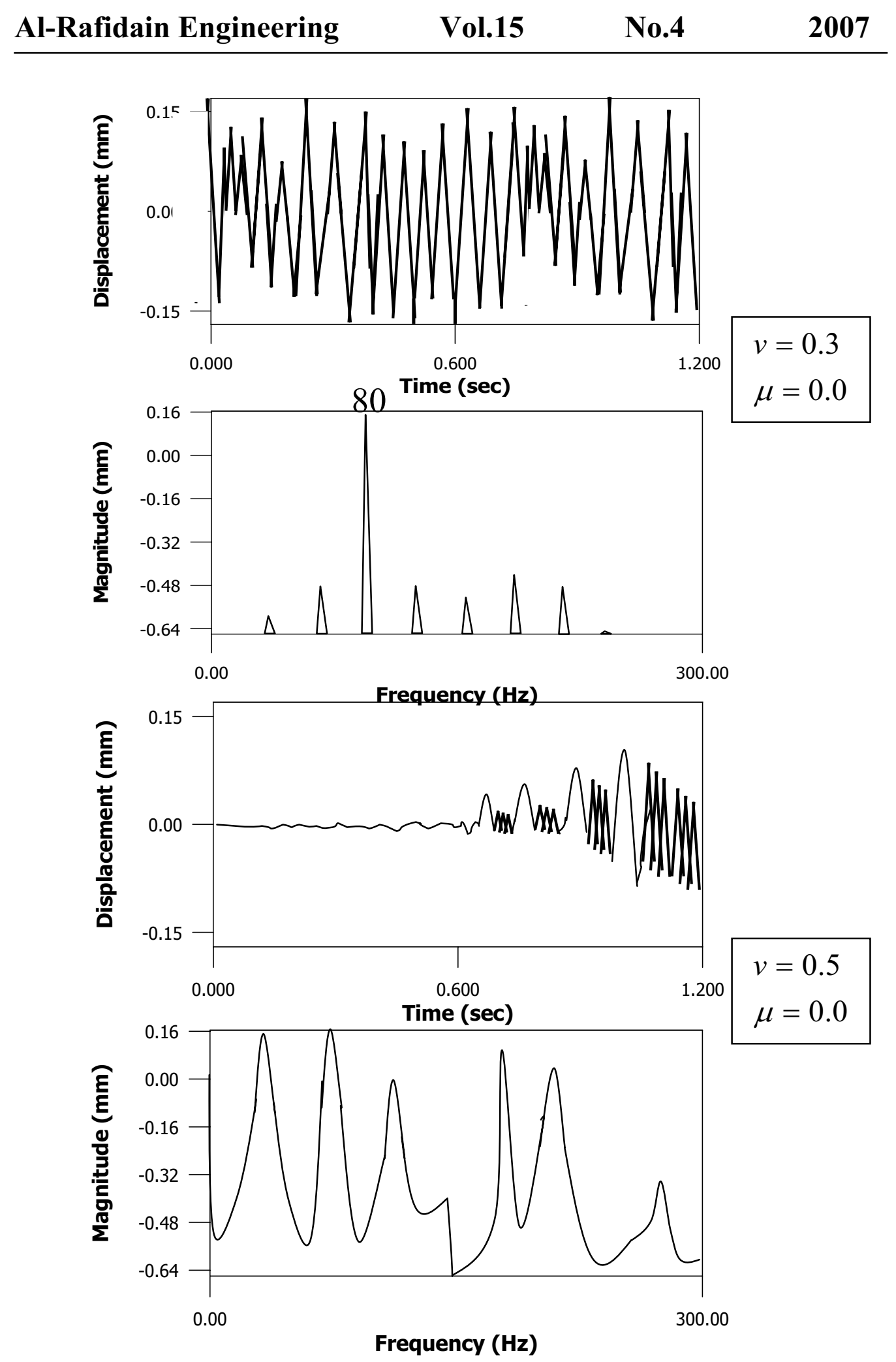

Fig.6 The Steady-State Response with Isotropic Cracked Shaft 

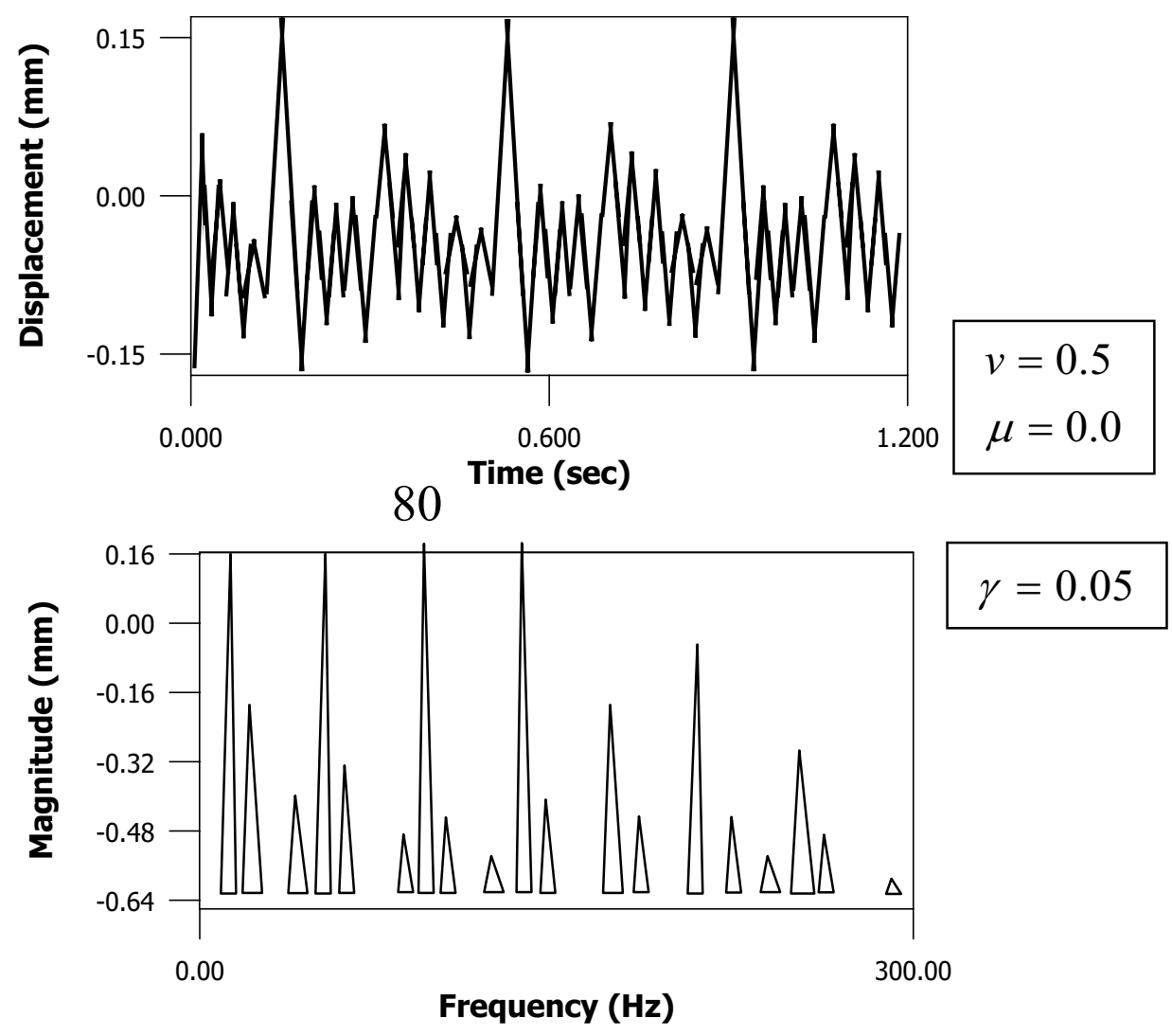

Fig.7 The Steady-State Response with Isotropic Cracked Shaft

$\mathrm{v}=0.5$, the system is unstable, however, by increasing the damping ratio $\gamma$ to 0.05 , it is become stable.

Consequently, the frequencies in the fixed coordinate system are represented by :-

$\omega_{n}=2 \Omega \pm n \frac{\omega_{T}}{2} \quad, \quad n=0,1,2,3,4,5, \ldots$

However, the even terms of (n) in Equation (28), only appear in the numerical results and the odd terms are missing as well as the steady-state response of the imbalance. The system becomes unstable when $(\mu)$ approaches to $(0.45)$ for $(v=0.3)$.

According to Eq.(25), the steady state response of the rotor system with a slant crack caused by an imbalance consist of the synchronous vibration and the subharmonic vibration at intervals of $\omega_{T} / 2$ centered at the operation speed $\Omega$. Therefore the frequencies can be determined by: 
$\omega_{n}=\Omega \pm n \omega_{T} \quad ; \quad n=0,1,2,3,4,5$,

The magnitude of vibration becomes larger with an increase in $\mathrm{v}$, on the other hand the ratios of the magnitude of the sub-harmonic vibrations to that of the synchronous vibration also become larger.

The system becomes unstable when the amplitude of vibration continuos to as $\mathrm{v}$ approaches to 0.5 , but returns to stable through damping.

\section{Conclusions}

The transverse vibration of the rotor system with a shaft having a slant crack has been investigated qualitatively using a simple rotor model under the assumption that the bending stiffness of the shaft changes synchronously with the opening / closing behavior of the crack caused by the torsional vibration, and the following conclusion may be drawn: -

(1) It is assumed that the slant crack continuos to open and close with the frequency $\omega_{T}$ of the torsional vibration, so that the bending stiffness of the shaft will oscillate synchronously with the torsional vibration. The motion of the rotor system with a slant crack is represented by a differential equation with parametric excitation in the coordinate system rotating at the operating speed $\Omega$ of the rotor as shown below:

$\xi^{\prime \prime}+H \xi^{\prime}+\left\{\left(\omega_{o}^{2}-\Omega^{2}\right) I\right\}=f$

(2) The frequencies of the steady state response of the cracked rotor system in the fixed coordinate system are represented by: -

$\omega_{n}=m \Omega+\frac{n \omega_{T}}{2}, m=1,2,3, \ldots, n=0,1,2, \ldots$

(3) Increasing the depth of the crack or the anisotropy of the shaft by the crack, the system becomes unstable. However, the damping is more efficient to return the system from unstable to stable state.

\section{References}

[1] Loeber, J. F. and Sih, G. C. "wave Scattering about a Slant Crack on a Bimaterial Interface, in Dynamic Crack Propagation”. (Ed. G. Sih), pp. 513528, Nordhoff, Leyden (1973).

[2] Inagaki, T. and Kanki, H. "Transverse Vibration of a General CrackedRotor Bearing System”, ASME Paper 81-DET-45,(1987). 
[3] Grabouski, B. P. and Mahreninoltzs, O. "Theoretical and Experimental Investigation of shaft Vibrations in Turbomachinery Excited by Cracks ", Energ.Eletter, Vol.59, No.10 (1983).

[4] Dimarogonas, A., and Massouros, G., "Torsional Vibration of a Shaft with a Circumferential Crack", Engineering Fracture Mechanics, Vol. 15, No.34, pp. 439-444, (1981).

[5] Morrow, H. W., "Static and Strength of Materials", $3^{\text {rd }}$ edition, Prentice Hall, (1998).

[6] Rao, S.S., "Mechanical Vibration", $3^{\text {rd }}$ edition, (1995).

[7] Gasch R. and Pfutzner, H. "Rotor-dynamic Einfuhrung”, J. Springer-Verlag (1980).

[8] Kodera, T. A. "New Method to Determine Unstable Regions of Parametric Excitation Systems",(In Japanese), Trans. Jpn. Soc. Mech. Eng., Vol.49, No.395, C., pp.747, (1980)

[9] Bueckner, H. F. "Field Singularities and related integral representations". In Methods of Analysis and Solution of Crack Problems, (Ed. G. Sih), pp. 239. Noordhoff, Leyden. (1973).

[10] Benthem, J. P. and Koiter, W. T. "Asymptotic approximations to crack problems". ibid, pp. 174-198. (1981).

[11] Chondros, T. G. and Dimarogonas, A. D. "Identification of cracks in circular plates welded at the contour”, ASME J. paper No.79-DET-106. Design Engng Tech, Conf., St. Louis, and U.S.A. (Sept. 1980). 